Revista Iberoamericana. Vol. LXIII, Núms. 178-179, Enero-Junio 1997; 129-140

\title{
LA MUJER COMO CIUDADANA: DESAFÍOS DE UNA COQUETA EN EL SIGLO XIX
}

\author{
POR \\ Nina Gerassi-Navarro \\ Mount Holyoke College
}

En 1850, el colombiano Aníbal Galindo escribió en el periódico El Neogranadino la siguiente reflexión con respecto a la convención de los derechos de la mujer que se realizó ese mismo año en los Estados Unidos:

\begin{abstract}
¿Podrá la mujer tener los mismos derechos del hombre? Reduciendo más la cuestión: ¿podrá la granadina ser ciudadana? Tan amante del bello sexo como ninguno siento en el alma responder por lo negativo ... ¿ ¿cómo puede la mujer pretender la ciudadanía cuando carece de independencia ..? La mujer está destinada especialmente a ser la compañera del hombre ... el mismo Dios lo mandó así ..; la naturaleza misma las corrobora... Por otra parte, qué chocante nos será ver a la mujer abandonar sus quehaceres y salir al campo eleccionario ... ¿qué sería del hogar doméstico vuelto al foco de querellas y debates? ¿qué de la familia? ... ¿qué del respeto y la moralidad en una casa donde no se sabría quién era el amo?'
\end{abstract}

Las razones que presenta Galindo justificando la posición inferior de la mujer contradicen el ethos de la sociedad burguesa que apelaba a la igualdad de oportunidades para todos. La mujer no puede tener acceso a los mismos derechos del hombre porque su función principal dispuesta por la naturaleza —el ser madre - se lo impide. La maternidad y el cuidado de su hogar la consume toda. El uso de las teorías biológicas para legitimar las desigualdades sociales entre clase y género, colocó a la mujer en una posición de subordinación y permitió definir como "naturales" hechos que eran decididamente "sociales". Consecuentemente, el lugar de la mujer y su rol en la sociedad quedaron restringidos al espacio doméstico donde su función principal era asegurar la permanencia de determinados valores morales (definidos por el hombre de la casa) y mantener unida la estructura familiar. Pero también se desprende de la afirmación de Galindo que si la mujer tuviera la posibilidad de verbalizar sus opiniones podría cuestionar las decisiones de su esposo. Es decir que la mujer sería capaz de disentir con su cónyugue lo cual, según el autor, crearía una ruptura en el ámbito doméstico, desestabilizando la unión más sagrada y básica de la sociedad. En conclusión, para mantener esa unión familiar y evitar todo tipo de desorden, la mujer debería permanecer al margen del ámbito político, bajo el control de su esposo.

${ }^{1}$ El Neogranadino, septiembre 6 de 1850, citado en Bermúdez. 
Frente a esta justificación para negarle el voto a la mujer, también se encuentra otra argumentación que sostiene que la mujer no debe tener acceso al voto porque justamente es incapaz de tener una opinión independiente. Darle el voto sería desperdiciar un derecho según Juan de Dios Restrepo:

La mujer llevaría a la urna electoral la opinión de su marido, padre, hermano o amante. Estamos seguros de que ellas no harán uso de semejante derecho y si lo hicieran nada ganaría la política aunque sí perderían mucho las costumbres ... quédense en la casa ... quédense allí... ${ }^{2}$

Por un lado se condena la disensión porque fragmenta y por otro, se condena el acuerdo por ser una mera repetición. Así se definen las dos posibilidades actanciales cuando se refieren a la mujer. Aún cuando las mujeres habían participado de diversas maneras en las guerras de independencia de la Gran Colombia, y la sociedad reconocía su valor, se les seguía negando la participación directa en las instituciones formales de poder. ${ }^{3}$ Este tipo de disyuntiva colocó a la mujer en un vacío paralizante ante lo cual la única alternativa era mantenerla en su lugar de "costumbre", dejarla inmóvil, ausente.

Durante el período de posindependencia, las discusiones ideológicas que dominaron el debate de la construcción nacional y del ciudadano ideal ocuparon un lugar central en la producción literaria de la época. La literatura adquirió una función didáctica a través de la cual se intentaba promover el perfeccionamiento de la vida republicana y democrática, edificando a la vez moral y políticamente al ciudadano. La literatura creó un espacio imaginario para proyectar al ciudadano ideal y diseñar un futuro próspero de nación. En ese proyecto, si bien los derechos y obligaciones de la mujer dentro de la "comunidad imaginada" fueron discutidos, su esfera de acción permaneció restringida al hogar. ${ }^{4}$

Las opiniones dispares acerca de la definición de la mujer y de su rol en la nación decididamente incideron en el modo en que ellas proyectaron sus representaciones a través de la literatura. Aún aquellas mujeres privilegiadas que lograron ocupar un espacio público y articular una voz propia no fueron ajenas a este conflicto. Posicionada dentro y fuera de la nación simultáneamente, la mujer debió encontrar una forma de encubrir su voz para poder acomodarse al discurso patriarcal sin romper abiertamente con los valores establecidos y, a la vez, encontrar una manera para explorar su rol e identidad en la sociedad. De allí surge ese discurso doble, lleno de contradicciones, que a menudo caracteriza la producción literaria de la mujer durante el siglo XIX. Mi interés es detenerme justamente en esas contradicciones porque considero que es allí donde se puede entender el modo en que las mujeres intentaron articular sus propias representaciones e inscribirse en el proyecto nacional de su país.

Entre las mujeres que participaron en la reorganización nacional de su país, se destaca la colombiana Soledad Acosta de Samper (1833-1913), una de las escritoras más prolíficas

\footnotetext{
${ }^{2}$ Juan de Dios Restrepo (Emiro Kastos), El Tiempo 14 de agosto de 1855, citado en Bermúdez 126.

${ }^{3}$ Véase Cherpak 219-234.

${ }^{4}$ Me refiero a la noción de "comunidad imaginada" elaborada por Benedict Anderson (véanse especialmente las páginas 13-16).
} 
del siglo XIX. Hija de padre diplomático, militar y reconocido hombre de estado, Acosta de Samper creció inmersa en las discusiones patrias. Su educación fue excepcional para una mujer de su época ya que por las misiones gubernamentales de su padre residió y estudió en Quito, Santa Fe de Bogotá, Washington y París. ${ }^{5}$ Su casamiento con José María Samper, prominente político, periodista y escritor, además de ser una de las figuras intelectuales más influyentes del siglo XIX en Colombia, le permitió el acceso a un mundo poco frecuentado por mujeres, desde donde usó su posición de privilegio para luchar por los derechos de la mujer incitándola a hacer algo "útil" de su vida. Una vez iniciada su labor de escritora, Acosta de Samper nunca la abandonará, ni siquiera cuando tenga que trabajar comercialmente para mantener a su familia. Sus primeros escritos son traducciones y crónicas de viajes y de la vida cotidiana. También colaboró como editora y correctora en la Revista Americana, una publicación fundada en Lima por su esposo con el fin de promover la literatura del Perú. Luego, bajo varios seudónimos ("Andina", "Bertilda", "Olga" y "Renato" entre otros) publicó una serie de novelas y narraciones que posteriormente formarían una colección titulada Novelas y cuadros de la vida sur-americana. Su dedicación a la escritura la llevaría a colaborar en numerosas publicaciones como La Prensa, La Ley, Biblioteca de Señoritas, La Nación, El Deber y El Mosaico, produciendo un corpus verdaderamente impresionante que abarca desde reportajes, estudios, editoriales, cuadros de costumbres, hasta biografias de figuras patrias, cuentos y novelas. ${ }^{6}$

Tanto en sus escritos periodísticos como en sus obras de ficción, Acosta de Samper despliega una preocupación no sólo por el futuro de su país sino, y sobre todo, por el rol que la mujer debía ocupar en ese proyecto. A pesar de discutir la importancia de la mujer en la sociedad e insistir en su reconocimiento e independencia, Acosta de Samper la excluye del campo de la política y, sin cuestionar los parámetros establecidos por la sociedad patriarcal, incita su participación dentro del campo doméstico donde, en su opinión, puede ejercer mayor influencia. Con este propósito funda y edita varias publicaciones como La Familia, Lecturas para el hogar y La mujer, un periódico publicado exclusivamente por mujeres, donde se discuten los diferentes modos de participación de la mujer:

[...] la mujer no debe participar activamente en la política. Lejos de nosotros la idea de abogar por la absurda emancipación de la mujer, ni pretendemos pedir que ella aspire a puestos públicos, ni que se le vea luchando en torno a las mesas electorales, no, esa no es su misión, e indudablemente su constitución, su carácter y naturales ocupaciones no se lo permitirán jamás. Pero quedaría para ellas la parte más noble, la influencia moral en las cuestiones trascendentales y fundamentales de la sociedad [...] ella tiene el deber de comprender qué quieren y a lo que aspiran los partidos, entonces ejercería su influencia (Acosta de Samper citada por Bermúdez 127).

\footnotetext{
${ }^{5}$ Para más datos biográficos véase Montserrat Ordoñez.

${ }^{6}$ Según la bibliografía preparada por Gustavo Otero Muñoz, la obra de Acosta de Samper se extiende desde 1862 hasta 1906, y abarca un total de 48 narraciones breves y 21 novelas. Otero Muñoz señala que sus primeras labores como escritora se hallan publicadas en la Biblioteca de señoritas a partir de 1858.
} 
El rol fundamental de la mujer es asegurar su influencia moral dentro de la casa. Partiendo de las características "naturales" asignadas a la mujer y consciente del vínculo entre la familia y la comunidad política, Acosta de Samper subraya el rol constructivo de la mujer dentro de la nación. Si bien la mujer no debe participar en política, debe "entender los partidos" o sea que debe comprender cuáles son los valores y principios que distinguen a cada partido para poder asegurar que la familia reproduzca aquellos valores considerados indispensables para el futuro de la nación. La familia se convierte en el emblema de los futuros ideales nacionales. Para que un determinado proyecto político logre consolidarse dentro de la sociedad debe estar arraigado en el hogar. Siendo éste el aceptado dominio de la mujer, será ella quien, a través de su influencia moral, asegure su afianzamiento. En este sentido la inclusión de la mujer en el proyecto político nacional es indispensable.

En los debates sobre la consolidación nacional, la mujer pocas veces aparece pensada como ciudadana. ${ }^{7}$ Su función es más bien acompañar y reproducir los ideales de su esposo o padre. Ella es la encargada de poblar la nación, determinada y defendida por los hombres. En su capacidad reproductiva, la mujer no puede ser soberana, sólo puede imaginarse dependiente. Su cuerpo, símbolo del futuro, la margina de la hermandad de hombres que luchan por el bienestar de todos. Por ello, como lo observó de Dios Restrepo, darle la voz y voto a la mujer era un desperdicio.

A pesar de defender fervientemente los derechos e independencia de la mujer, Acosta de Samper no reclama el derecho de voto ni cuestiona el discurso paternalista. Pero en lugar de esperar pasivamente que los hombre definan el proyecto nacional, cree firmemente en el rol activo de la mujer y aboga por que ella se posicione junto al hombre en su lucha. En lugar de verla como dependiente, prefiere imaginarla como aliada:

No somos diosas ni esclavas, ni los hombres son ya héroes ni semidioses; debemos trabajar a su lado, aunque en diferentes caminos, y nuestra importancia y valor serán los que queremos. $^{8}$

Diferentes, pero situadas al unísono con los hombres, este es el nuevo rol por el que debe luchar la mujer. El mensaje de Acosta de Samper se desdobla sutilmente. Por un lado insiste en destruir imágenes que congelen y paralicen tanto el lugar y trabajo de los hombres como el de las mujeres. Asegurándoles a los hombres su supremacía, les recuerda que a través del hogar la mujer también tiene un rol similar al de ellos en la consolidación nacional. Por esta razón deben incluirla en todo proyecto político. Simultáneamente su mensaje se dirige a las mujeres y, cuestionando su subordinación, las incita a que trabajen por su propia valoración, que traten de hacer algo constructivo con sus vidas. La responsabilidad de la mujer es educarse justamente para poder cumplir con el mandato que le han asignado los hombres. Es por medio de este acto que la mujer puede trascender los límites de su hogar y tomar entre manos la redefinición de su rol en la sociedad. Pero, como afirma Acosta de Samper, esta es una decisión que las mujeres deben tomar por sí mismas.

\footnotetext{
${ }^{7}$ En Colombia la mujer tendrá el derecho de votar a partir de 1957. Para una historia del voto de la mujer en Latinoamérica véase Jacquette.

${ }^{8}$ Acosta de Samper, La Mujer (20 de mayo de 1879), citado en Bermúdez 130.
} 
Su obsesión por la educación de la mujer la lleva a enmarcar sus ficciones con reflexiones que se transforman en numerosas ocasiones en una ilustración de lo que ocurre en la vida real cuando la mujer carece de una buena educación. De hecho sus novelas se caracterizan por la propuesta de diferentes soluciones ficcionales ante los problemas diarios que atañen a la mujer.' Si bien reconoce que en cierta forma la educación también es un mecanismo de control social (ya que se la educa según determinados parámetros establecidos por la sociedad patriarcal), Acosta de Samper está convencida de que es la única forma de otorgarle a la mujer una herramienta que le permita construir un eje propio que trascienda el espacio doméstico. Sus cuadros sobre la vida de la coqueta ejemplifican esta ambigüedad. Se trata de dos cuentos distintos, uno a continuación del otro, casi idénticos con la diferencia de que uno presenta la mirada del hombre y el otro, la de la mujer. Lo interesante de este formato es que al comparar dichas versiones de la "realidad" respresentada, las sutiles diferencias revelan dos modos de percepción, dos formas de definir a la mujer claramente opuestas, una cuestionando a la otra.

Los cuentos, "La perla del valle" y "Luz y sombra", forman parte del primer volumen de obras de Acosta de Samper titulado Novelas y cuadros de la vida sur-americana, publicado en Bélgica, en 1865. ${ }^{11}$ Dicho texto aparece autorizado por su marido, quien se adjudica el control de la producción literaria de su esposa:

La idea de hacer una edición en libro, de las novelas y los cuadros que mi esposa ha dado a la prensa, haciéndose conocer sucesivamente bajo los seudónimos de Bertilda, Andina y Aldebarán, nació de mí exclusivamente; y hasta he tenido que luchar con la sincera modestia de tan querido autor para obtener su consentimiento. [...] ¿Por qué lo he solicitado con empeño? [...] He querido, por mi parte, que mi esposa contribuya con sus esfuerzos, siquiera sean humildes, a la obra común de la literatura que nuestra joven república está formando, a fin de mantener de algún modo, la tradición del patriotismo de su padre. ${ }^{12}$

La apropiación de Samper casi silencia el lugar de su esposa como autora. No sólo se atribuye a sí mismo la publicación del texto sino que además subraya que el propósito de dicha publicación es mantener vivo el "patriotismo de su padre", hecho que apenas reconoce el valor del trabajo literario en sí. Si bien el aporte de Acosta de Samper es en cierta forma una contribución a la nueva república, su espacio y figura quedan claramente enmarcados por las "verdaderas" figuras patrias: la paterna y la de su esposo. Por otra parte al catalogar la obra de su esposa como parte de la producción literaria de la joven república en formación, el subtexto implica cierta inmadurez como característica principal de su escritura. Pero Acosta de Samper usa esta forma de legitimidad para autorizar su reivindicación de la mujer. De hecho sus escritos a menudo aparecen con la introducción de una figura masculina consagrada (su esposo, el presidente de la nación), cuya función es autorizar, legitimar su

${ }^{9}$ De hecho la obra narrativa de Acosta de Samper se caracteriza por la propuesta de diferentes soluciones ficticias ante los problemas diarios que atañen a la mujer en el siglo XIX. Véase Rodríguez-Arenas y Guerra Cunningham.

${ }^{10}$ Soledad Acosta de Samper, Novelasy cuadros de la vida sur-americana. Todas las citas procederán de esta edición.

${ }^{11}$ José María Samper, "Dos palabras al lector", en Acosta de Samper vii-viii. 
escritura. Acosta de Samper usa esa autoría de la mirada masculina para luego oponerla o unirla a la mirada femenina. Miradas que dialogan entre sí, dibujando espacios que sutilmente se van desdoblando y separando hasta permitir que se distingan dos voces totalmente independientes.

Ambos relatos presentan la vida de la coqueta en dos etapas: la preciosa juventud, durante la cual la belleza de la mujer deslumbra a todos los hombres, aunque su vanidad la lleva a rechazar todas las propuestas de matrimonio. Luego, llega la vejez ( 15 años después), cuando las mujeres tienen 30 años y están casi irreconocibles, desgreñadas, arrugadas, viejas e infelices. En la primera historia, "La Perla del valle", el narrador es un joven apuesto de la ciudad quien, al encontrarse con su coqueta años después y verla tan venida a menos, le comenta a su amigo:

¡Qué lección para las mujeres que creen que pueden ser coquetas impunemente!.. Lo que faltó principalmente a esa niña fue una buena educación que pudiera impedir que se desarrollasen en ella los perniciosos impulsos que naturalmente debían dominarle en su posición excepcional como perla de la aldea (361).

En ambos cuentos la mujer es presentada como un objeto estético con rasgos casi idénticos: rubias, de pelo largo trenzado, ojos negros, labios marcados y tez blanca. Es la visión romántica de la mujer americana, la criolla. Pero su belleza es estática. Al carecer de características individuales, todas las mujeres se convierten en un único cuerpo estético representando la virginal belleza americana. En el primer relato esto es particularmente notable ya que todas las mujeres carecen de nombre, son "bellezas", siendo la más linda la Perla. Además de los rasgos genéricos tipificadores, las mujeres en este relato carecen de voz. El espectador masculino no le cede la palabra al personaje central, quien literalmente no dice mucho más que "gracias". La voz masculina narra, decodifica y explica. Su mirada representa la ley desde la cual se decreta el lugar de la mujer.

En la medida en que es el hombre quien determina el rol de la mujer y define su espacio, la desdicha de la Perla resulta doblemente trágica porque su recuerdo idealizado está íntimamente vinculado con la simbología patria:

en medio de los combates y sufrimientos de las guerras civiles, llenas de violencias y peligros, la suave figura de la Perla del Valle se me apareció como la imagen de la patria ausente, como la personificación de un sueño de dicha entrevisto en la juventud, como una promesa de virtud y de plácida alegría ... (356).

La bellezajuvenil de la Perla corporiza la potencialidad de la nueva nación emancipada, la "promesa de virtud". Pero al ignorar ese futuro y volcarse sólo al presente, la Perla se corrompe, pierde su sentido de responsabilidad y pone en peligro el futuro y virtud de la nación. Su fracaso por ende, es tambien el fracaso de la nación, de allí la necesidad de reprender su actitud.

Lo condenable de la coqueta según el narrador, es no saber controlar su belleza para mantenerse como objeto estético y a la vez subordinar esa belleza a la formación de una familia. La coqueta usa su belleza y, en lugar de subordinar su mirada a la masculina, la vuelve hacia sí misma, concentrándose en su propio cuerpo. Su pecado es el exceso: 
excesivamente bella, excesivamente central; y el exceso lleva al derrumbe, al fracaso, lo cual justifica su castigo. Es la imposición de la ley y orden patriarcal. La educación, en este sentido, es presentada como medio de salvación para la mujer. Su función es también censora, pues la enmarca en un espacio/imagen/rol predeterminado por los hombres.

En el cuento, a pesar de ser la hija de uno de los principales habitantes del pueblo, admirada y consentida por todos, la Perla termina siendo excluida por su comunidad. La explicación es que "se hizo coqueta, y esa coquetería quedando sin fruto, fué progresando de día en día" (360) hasta ser obligada por la buena sociedad a vivir entre los más humildes del pueblo. El error no fue ser vanidosa sino que la Perla no usó su belleza para "casarse bien". Las consecuencias de quebrar las reglas son serias: llevan a la pérdida de estatus, al ostracismo o a la muerte.

¿De qué forma cuestionar ese orden? ¿De qué otro modo mirar a la coqueta? En la segunda narración, Acosta de Samper ofrece una alternativa, aunque a primera vista parecería avalar la misma construcción de lo femenino. La protagonista, Aureliana Hernández, ya entrando en años (30), acepta cumplir con el mandato a pesar de que no quiere al hombre con quien se casa y sabe que él tampoco la quiere. El resultado es que años después, enferma y frágil, Aureliana terminará ignorada por su familia e inclusive por su esposo. Morirá sola. A modo de epígrafe la narradora agrega:

y esto me ha probado una vez más, cuan indispensable es para la mujer una educación esmerada y una instrucción sana, que adorne su mente, dulcifique sus desengaños y le haga desdeñar las vanidades de la vida (396).

El sombrío final de la protagonista ilustra el mensaje social del relato: la felicidad de la mujer dependenderá de su cumplimiento con el mandato patriarcal cuyo orden es justificado porque asegura el bienestar de sus habitantes. Por otra parte la mujer sólo podrá sentirse realizada si es capaz de constituir una familia según el modelo que asegure el ideal nacional.

La diferencia fundamental entre esta narración y la anterior, radica en la mirada de quien relata, una mujer. Ante la belleza de Aureliana, la narradora tiene una reacción más compleja que la del hombre. Por un lado la rechaza al ver su vanidad y por otro se deslumbra: "Era tal la impresión que Aureliana me había causado, que no podía apartar mi vista de su precioso rostro" (383). El placer de la mirada ya no es exclusivamente masculino. La mujer es capaz de admirarse a sí misma a través de la imagen/belleza de la coqueta. Quien mira además es quien ejerce el control sobre la narración. Ese es el poder del sujeto. En un acto solidario, Mercedes, la narradora, le cede la palabra a Aureliana para que ella cuente su propia historia, para que ella misma se explique. El relato ficticio queda ahora enmarcado por las dos mujeres. Y es aquí donde se redefine no sólo la figura de la coqueta sino tambien la construcción de lo femenino.

Uno de los temas centrales de conversación entre las dos mujeres es la importancia del amor en la constitución de la pareja, que alude al nuevo tipo de familia que surge con la emancipación. Durante la colonia, el matrimonio tuvo poco que ver con el amor. Los casamientos se producían más bien por obligación o por razones religiosas. Entre las familias más acomodadas, era una alianza para asegurar su patrimonio y estatus social, un 
modo de perpetuar el sistema jerárquico de hegemonía española (Navarro 28). ${ }^{12}$ Pero a partir de 1800, los censos matrimoniales revelan una nueva razón: el amor. En Colombia, Susy Bermúdez afirma que si bien no llega a imponerse legalmente, a partir de la independencia política la presencia del amor entre la pareja comienza a ser justificada (Bermúdez 115). ${ }^{13}$ Sin embargo, a pesar de esta ilusión de igualdad, implícito en la idea de que existe un consenso afectivo entre ambos miembros, el matrimonio continuó siendo un contrato que obligaba a la mujer a postergarse en favor del "otro", asegurando así su subordinación.

Aureliana le confiesa a su interlocutora que su drama es no haber podido encontrar a un hombre al que realmente pudiera amar. Tristemente refiere sus conquistas e intentos de parejas que siempre terminaban en desilusión:

He pasado mis días buscando con ahinco el amor, único objeto de la vida de una mujer, pero en su lugar solo he hallado desengaños y vacío. No creas que la coquetería que me tachan quizás con razón, es el fruto de un corazón pervertido: no lo creas: es que busco en todas partes un ideal que huye de mi incesantemente (390).

Esta confesión presenta una nueva definición de la coquetería: es esencialmente una búsqueda dentro de la cual la mujer se posiciona como sujeto responsable. La única culpa de Aureliana es intentar cumplir con el ideal social de casarse por amor. La contradicción, sin embargo, radica en que para la sociedad esto es inaceptable en una mujer en la medida en que ésta se vuelva exigente. Como ideal, casarse por amor es importante, pero si la mujer se posiciona como centro y vuelca su mirada hacia los hombres como objetos, esto resulta nocivo. Vista a través de la mirada femenina, la coquetería articula la ambigüedad de las expectativas sociales asignadas a la mujer. Acosta de Samper lleva aún más lejos esta disyuntiva al contrastar la punible situación de la coqueta, su soledad y abandono, con la supuesta felicidad de la narradora quien está a punto de casarse. Pero cuando ésta define qué significa amar, el panorama resulta poco alentador:

Hace dos años ... que estoy comprometida a casarme y nunca me ha pesado. Esto le bastará a usted para comprender que sé lo que es amar (386).

Lo revelador de estas relfexiones es que ponen en evidencia la falta de los hombres. En su búsqueda de amor, Aureliana sólo encuentra vacío y frivolidad. Son los hombres quienes resultan incapaces de entregarse realmente; el interés que muestran por las mujeres es un mero juego de conquista que recubre su propia superficialidad. Aureliana llega a la conclusión de que "todos los hombres son iguales puesto que basta lisonjear su vanidad para

\footnotetext{
${ }^{12}$ El cambio fundamental se produce a partir de 1776 con la promulgación de la cédula real (Real Pragmática) por el rey Borbón, Carlos III, en la cual se redefine dramáticamente la reglamentación del casamiento. Para un análisis sobre este período de transición y el modo en que dichos cambios afectaron el rol de la mujer en la sociedad colonial véase Socolow.

${ }^{13}$ Doris Sommer rastrea el modo en que las novelas durante este siglo reafirman la correlación entre la unión amorosa de una pareja y el ideal nacional que dicha pareja reproducirá al consolidarse.
} 
verlos rendidos" (389). La coqueta expone la insuficiencia de los hombres a través de sus juegos y seducciones. El verdadero peligro de permitirle a la mujer que verbalice sus propias opiniones es que posee la capacidad de desestabilizar el orden social al reclamarle a los hombres su falta de responsabilidad. Como explica la narradora al reflexionar sobre Aureliana, "Sin educación esmerada, sin instrucción ninguna, al perder esa hermosura que era su único atractivo, los admiradores fueron abandonándola sucesivamente" (394). La superficialidad de los hombres es que mientras la mujer sea bella y joven aceptan su falta de educación, pero una vez que comienza a envejecer, ella ya no tiene ningún atractivo. Aquí es donde Acosta de Samper sutilmente cuestiona la idea de casarse por amor y redefine la función de la educación convirtiéndola en un arma, un medio para otorgarle a la mujer cierto poder para no encontrarse completamente supeditada al hombre (Ordóñez 20).

Consciente de su belleza, la coqueta usa su cuerpo para agradar a los hombres. En la medida que su centro de atención está puesto en él y subordina su existencia a su propia mirada, la mujer se coloca como objeto. Aquí no habría ningún acto censurable según los cánones sociales. Lo condenable es que la coqueta use su belleza para convertirse en sujeto de su propia mirada. Ese es el momento en que la mujer cruza la frontera del espacio designado. Al colocarse como objeto y sujeto de su propia historia, la mujer se construye como emblema del narcisismo puro. La amenaza real de las coquetas es que se complacen en su propia sexualidad y desplazan al hombre. El deseo de la coqueta se convierte en el elemento central de su existencia y el hombre queda fuera del eje estructurador.

Al final del relato, a modo de epígrafe, se articula la moraleja de la historia por una segunda narradora:

Este episodio me fue referido no ha mucho por una venerable matrona de ***, y esto me ha probado una vez más, cuán indispensable es para la mujer una educación esmerada y una instrucción sana, que adorne su mente, dulcifique sus desengaños y le haga desdeñar las vanidades de la vida (396).

Según Acosta de Samper la educación es indispensable para la mujer porque le ofrece una alternativa ante el vacío político de su rol tradicional. La mujer debe aprender a reconocer y desdeñar las vanidades de la vida, pues esas vanidades son las que la supeditan a la mirada del hombre. La injusticia es que a pesar de tener un rol para la nación claramente delineado como madre y esposa, la mujer no logre un reconocimiento político por ello.

A pesar de la importancia que adquiere el matrimonio como institución durante el siglo $\mathrm{XIX}$, los beneficios son sumamente dispares para los hombres y para las mujeres. Para el hombre, el estar casado reflejaba su responsabilidad y lo habilitaba para ser ciudadano. Esta es una de las características que permanece fija a través de las reformas constitucionales de Colombia. Tanto en la constitución de 1853 como en la de 1863, el ser mayor de 21 y/o ser casado es uno de los requisitos para ser ciudadano, pero esto no atañe a la mujer. Por más que ella cumpla con sus deberes y vele por el bienestar de su familia, la responsabilidad de ser madre de familia nunca se equipara a la del padre. En su estudio sobre la mujer y familia en Colombia, Bermúdez señala que esta desigualdad en la conceptualización de la paternidad frente a la maternidad seguirá siendo reforzada posteriormente, como lo evidencia la propuesta de Miguel Antonio Caro, quien abogaba por el voto múltiple para los padres de familia: 
No sería justo decretar que solo los padres de familia voten; pero si ha de votar todo el mundo, sería muy bien pensado que el voto del padre de familia pesase como dos o más votos, como que un padre de familia no es un individuo aislado, sino legítimo jefe y representante de su pequeño reino (Cruz Santos 294).

Si bien el lugar de la mujer es el espacio privado del hogar, el hombre es el jefe de ese "pequeño reino", y como tal es el verdadero representante legal de la sociedad. Aún cuando la mujer cumpla con su mandato social, el estar al frente de su familia no le otorga privilegios de ningún tipo. Acosta de Samper reconoce esta desigualdad y por ello ve la educación como un medio para que la mujer se reafirme con cierta independencia en la sociedad. De hecho, a partir de la segunda mitad de siglo, una de las vías principales por las cuales las mujeres penetran en el dominio público es a través de su función pedagógica (Sarlo 233). Como maestras, informales dentro el hogar y formales en las escuelas, las mujeres aseguran la reproducción de la ideología nacional y refuerzan el vínculo entre la familia y el estado. Acosta de Samper reconoce este rol y por ello en numerosos ensayos dirigidos a las mujeres, les recomienda fervientemente el orden, la disciplina y la ocupación como elementos claves en la educación de las niñas:

[...] obligar a las niñas desde su tierna infancia a tener siempre una ocupación, a que observen un régimen higiénico sano [...] evitar conversaciones inútiles, vigilar sus amistades, sus lecturas, y sobre todo no permitir que piensen que la vida es fastuosa para nadie, puesto que en ella cada cual debe cumplir arduos deberes. ${ }^{14}$

Dejando de lado el romanticismo que encubría el casamiento ideal, Acosta de Samper aboga por la formación de la mujer para que ésta pueda ser una verdadera compañera. Subraya la importancia de preparase para se una participante útil y constructiva en la pareja. Reafirmando el rol tradicional de la mujer, Acosta de Samper delinea un nuevo espacio para la mujer en la sociedad de su época, liberándola de su función de madre y esposa exclusivamente para incluirla en la esfera de la producción económica. La imagen que construye de la coqueta refleja el modo en que inteligentemente Acosta de Samper busca quebrar los moldes rígidos sin cuestionar la ley patriarcal.

Los cuadros de la coqueta articulan algunas de las contradicciones del lugar asignado a la mujer en la sociedad hispanoamericana durante el siglo XIX. Pero más importante aún, estos relatos exponen la ambigüedad de la construcción de lo femenino y el modo en que mujeres como Acosta de Samper intentaron revelar las contradicciones de las representaciones de la mujer para crear un espacio literario y político en que ellas mismas pudieran explorar y cuestionar esa imagen. En esos insterticios marcados por las contradicciones podemos encontrar otras imágenes que aún tienen mucho que decirnos sobre la problemática que debió enfrentar la mujer para construir su propia identidad en la literatura en el siglo XIX.

${ }^{14}$ Acosta de Samper La Mujer (21 de febrero de 1879), citado en Bermúdez 133. 


\section{BibLIOGRAFÍA}

Acosta de Samper, Soledad. Novelas y cuadros de la vida sur-americana. Gante: Imprenta de Eug. Venderhaeghen, 1869.

Anderson, Benedict. Imagined Communities: Reflections on the Origin and Spread of Nationalism. London: Verso and New Left Books, 1983.

Bermúdez, Susy Denise. "Debates en torno a la mujer y la familia en Colombia, 18501886". Texto y contexto. Bogotá: Presencia, (enero-abril 1987): 111-144.

Castro-Klarén, Sara; Sylvia Molloy y Beatriz Sarlo, eds. Women's Writing in Latin America. Boulder, Colorado: Westview Press, 1991.

Cherpak, Evelyn. "The Participation of Women in the Independence Movement in Gran Colombia, 1780-1830". Sexuality \& Marriage in Colonial Latin America. Asunción Lavrín, ed. Lincoln: University of Nebraska Press, 1989. 219-234.

Cruz Santos, Abel. Antecedentes de la Constitución de Colombia de 1886. Bogotá: Academia de la Historia, 1983.

Guerra Cunningham, Lucía. "La modalidad hermética de la subjetividad romántica en la narrativa de Soledad Acosta de Samper". Soledad Acosta de Samper: una nueva lectura. Bogotá: Fondo Cultural Cafetero, 1988. 353-367.

Jaquette, Jane. "Female Political Participation in Latin America". Sex and Class in Latin America. June Nash y Helen Icren Safa, eds. New York: Praeger Publishers, 1976. 221-244.

Jaramillo, María Mercedes, Angela Inés Robledo, y Flor María Rodríguez-Arenas. ¿Y las mujeres?: ensayos sobre literatura colombiana. Medellín: Universidad de Antioquia, 1991.

Lavrín, Asunción, ed. Sexuality \& Marriage in Colonial Latin America. Lincoln: University of Nebraska Press, 1989.

Nash, June, and Helen Icken Safa, eds. Sex and Class in Latin America. New York: Praeger Publishers, 1976.

Navarro, Marysa. "Women in Pre-Colombian and Colonial Latin America". Restoring Women. Restoring Women to History! Teaching Packets for Integrating Women's History into Courses on Africa, Asia, Latin America, the Caribbean, and The Meddle East. Bloomington: Organization of American Historians, 1988. 3-40.

Ordoñez, Montserrat. Introducción. Soledad Acosta de Samper. Bogotá: Fondo Cultural Cafetero, 1988. 11-24.

Otero Muñóz, Gustavo. Bibliografia. Soledad Acosta de Samper. Bogotá: Fondo Cultural Cafetero, 1988. 369-397.

Restoring Women to History: Teaching Packets for Integrating Women's History into Courses on Africa, Asia, Latin America, the Caribbean, and the Middle East. Bloomington: Organization of American Historians, 1988.

Rodríguez-Arenas, Flor María. "Siglo XIX. Soledad Acosta de Samper, pionera de la profesionalización en la escritura femenina colombiana: 'Dolores', 'Teresa la limeña' y el corazón de la mujer"”. ¿Y las mujeres?: ensayos sobre literatura colombiana. María M. Jaramillo, Angela J. Robledo y Flor M. Rodríguez-Arenas. Medellín: Universidad de Antioquía, 1991. 133-175. 
Sarlo, Beatriz. "Women, History and Ideology". Women's Writing in Latin America. Sara Castro-Klarén, Sylvia Molloy y Beatriz Sarlo, eds. Boulder, Colorado: Westview Press, 1991. 231-248.

Socolow, Susan M. "Acceptable Partners: Marriage Choice in Colonial Argentina, 17781810”. Sexual \& Marriage in Colonial Latin America. Asunción Lavrín, ed. Lincoln: University of Nebraska Press, 1989. 207-251.

Soledad Acosta de Samper: una nueva lectura. Bogotá: Fondo Cultural Cafetero, 1988. Sommer, Doris. Foundational Fictions: The National Romance of Latin America. Berkeley: University of California Press, 1991. 